(C) 1984. The Genetical Society of Great Britain

\title{
EVOLUTION OF THE OBSCURA GROUP DROSOPHILA SPECIES. II. PHYLOGENY OF TEN SPECIES BASED ON ELECTROPHORETIC DATA
}

\author{
M. LOUKAS, C. B. KRIMBAS AND Y. VERGINI \\ Department of Genetics, Agricultural College of Athens, Greece
}

Received 20.x.83

\section{SUMMARY}

\begin{abstract}
Nine palearctic and one North American Drosophila species of the obscura group have been compared with respect to electrophoretically detectable differences at 24 enzyme loci. The genetic distances between the species have been calculated. The constructed tree is divided into two evolutionary lineages. The first comprises the species $D$. pseudoobscura and $D$. helvetica and the second the palearctic species of the obscura subgroup. The latter splits into two lineages. One lineage leads to $D$. bifasciata and $D$. subsilvestris; the other splits further to two sublineages: the sublineage of $D$. obscura, D. tristis and $D$. ambigua and the sublineage of $D$. guanche, $D$. subobscura and $D$. madeirensis.
\end{abstract}

\section{INTRODUCTION}

The Drosophila species of the obscura group can be further clustered into two subgroups (Lakovaara and Saura, 1982): obscura and affinis. The obscura subgroup comprises fourteen palearctic species: $D$. obscura Fallen, $D$. ambigua Pomini, D. subobscura Collin, D. madeirensis Monclús, D. guanche Monclús, D. bifasciata Pomini, $D$. subsilvestris Hardy and Kaneshiro, $D$. tristis Fallen, D. eskoi Lakovaara and Lankinen, D. alpina Burla, D. imaii Moriwaki and Okada, D. eniwae Takada, Beppu and Toda, D. epiobscura Parshad and Duggal and D. tsukubaensis Takamori and Okada (1983). Among the American species of the obscura subgroup, D. pseudoobscura Frolova is the most widespread one, while among the species of the affinis subgroup, $D$. helvetica Burla is the only palearctic species: all others, belonging to this subgroup, are widespread in North America.

In this study we have constructed a phylogenetic tree based on electrophoretic data concerning ten species of the obscura group, nine belonging to the obscura subgroup and one to the affinis subgroup (table 1). The phylogeny is based on 24 gene loci coding for enzymes. Our aim is (i) to compare this phylogeny to that proposed by Lakovaara et al. (1976), since eight out of the 21 loci studied by them were not studied by us, while eleven loci were exclusively studied by us, and (ii) to compare the phylogeny of $D$. subobscura, $D$. madeirensis and $D$. guanche, based on chromosomal gene arrangements (Krimbas and Loukas, this issue), to that obtained by electrophoretic data.

\section{Material AND MethodS}

(i) Electrophoresis

Horizontal starch gel electrophoresis was employed to study the following enzyme systems: 6-phosphogluconate dehydrogenase (6-PGD); malate 
TABLE 1

The electrophoretic mobilities of the most common allozymes at 24 loci in 10 species of the obscura group

\begin{tabular}{|c|c|c|c|c|c|c|c|c|c|c|}
\hline \multirow[b]{2}{*}{ Enzymes } & \multicolumn{10}{|c|}{ Species } \\
\hline & ob & am & so & $\mathrm{ma}$ & gu & bi & ss & $\operatorname{tr}$ & ps & he \\
\hline 6-PGD & $1 \cdot 42$ & 1.42 & 1.00 & 1.00 & 0.95 & $1 \cdot 42$ & $1 \cdot 42$ & 1.42 & $1 \cdot 34$ & $1 \cdot 58$ \\
\hline$M d h$ & $1 \cdot 37$ & $2 \cdot 53$ & 1.00 & 1.00 & $1 \cdot 00$ & $2 \cdot 53$ & $2 \cdot 00$ & $2 \cdot 21$ & 1.68 & $3 \cdot 37$ \\
\hline$\alpha-G P D$ & $1 \cdot 00$ & $1 \cdot 00$ & 1.00 & 1.00 & $1 \cdot 00$ & 1.37 & $1 \cdot 00$ & 1.00 & 1.00 & $1 \cdot 00$ \\
\hline$I d h$ & 0.77 & 0.77 & 1.00 & $1 \cdot 10$ & $1 \cdot 00$ & 0.61 & 0.61 & 0.77 & $1 \cdot 17$ & $1 \cdot 17$ \\
\hline Phi & 1.08 & 1.08 & $1 \cdot 00$ & 1.08 & $1 \cdot 00$ & $1 \cdot 25$ & $1 \cdot 25$ & 1.08 & 1.00 & $1 \cdot 25$ \\
\hline Adh & 1.00 & 1.00 & $-1 \cdot 00$ & $-1 \cdot 00$ & -1.00 & $0 \cdot 29$ & 0.29 & $1 \cdot 00$ & $-1 \cdot 11$ & $-1 \cdot 78$ \\
\hline Odh & 1.00 & 0.90 & 1.00 & 1.00 & 1.00 & 1.00 & $1 \cdot 00$ & 1.00 & 1.07 & 0.96 \\
\hline$T_{0-1}$ & 3.55 & $1 \cdot 00$ & 1.00 & 1.00 & $1 \cdot 00$ & 1.00 & 1.00 & $3 \cdot 55$ & $\mathbf{S}$ & $\mathbf{S}$ \\
\hline$T 0-2$ & 1.00 & 1.04 & 1.00 & 1.00 & $1 \cdot 04$ & 1.00 & 1.04 & 1.00 & 1.00 & $2 \cdot 04$ \\
\hline$H k-1$ & 1.00 & $1 \cdot 15$ & 1.00 & $\mathbf{S}$ & 0.95 & $2 \cdot 48$ & 1.41 & $1 \cdot 15$ & 1.41 & 1.55 \\
\hline$H k-3$ & 1.00 & 1.00 & 1.00 & 1.00 & $1 \cdot 00$ & 0.99 & 1.00 & 1.00 & 0.99 & 1.00 \\
\hline Pep-1 & 1.06 & 1.50 & 0.40 & $\mathbf{S}$ & 1.94 & $2 \cdot 37$ & 1.50 & $1 \cdot 50$ & 1.06 & $1 \cdot 19$ \\
\hline Pep-2 & $1 \cdot 03$ & 0.98 & $1 \cdot 00$ & $1 \cdot 00$ & $1 \cdot 02$ & $1 \cdot 12$ & $1 \cdot 03$ & 0.98 & 0.94 & 1.03 \\
\hline Pep-3 & $1 \cdot 12$ & $1 \cdot 12$ & 1.00 & 1.08 & $1 \cdot 08$ & 0.85 & 1.09 & $1 \cdot 12$ & $1 \cdot 14$ & $1 \cdot 00$ \\
\hline$G-6-P D$ & 1.07 & 0.87 & 1.00 & 1.00 & $1 \cdot 15$ & $1 \cdot 15$ & $1 \cdot 15$ & 0.87 & $1 \cdot 15$ & 0.87 \\
\hline$M e$ & 0.72 & 0.82 & 1.00 & $1 \cdot 10$ & 0.84 & 0.92 & 0.72 & 0.91 & 0.54 & 0.91 \\
\hline Pgm-1 & 1.06 & 1.06 & $1 \cdot 00$ & 1.00 & 1.00 & 2.09 & 0.63 & 1.00 & 0.94 & 0.63 \\
\hline Pgm-2 & 0.90 & 0.90 & 1.00 & 1.00 & 1.07 & $2 \cdot 00$ & 0.40 & 0.90 & 0.80 & 0.40 \\
\hline Diaph & 1.06 & 1.06 & 1.00 & 1.06 & 1.06 & 0.94 & 1.06 & 1.06 & 1.06 & 1.06 \\
\hline Acph & 0.33 & $2 \cdot 50$ & 1.00 & 1.00 & $1 \cdot 00$ & 3.00 & $2 \cdot 50$ & 0.33 & 1.67 & 0.75 \\
\hline$A p h$ & $1 \cdot 42$ & 1.68 & 1.00 & 1.00 & 0.68 & 1.61 & 1.89 & 1.79 & 1.42 & 1.42 \\
\hline Ao & $1 \cdot 30$ & $1 \cdot 00$ & 1.00 & 1.07 & 1.07 & 1.04 & 1.04 & $1 \cdot 17$ & $1 \cdot 27$ & 1.00 \\
\hline Lap & 0.72 & 0.90 & 1.00 & 1.02 & 1.07 & 1.00 & 0.80 & 0.96 & 0.94 & 1.02 \\
\hline$X d h$ & 1.00 & 0.97 & 1.00 & 1.00 & 1.08 & 0.90 & 1.08 & 1.08 & 1.08 & $1 \cdot 12$ \\
\hline
\end{tabular}

Abbreviations used: $\mathrm{ob}=D$. obscura; $\mathrm{am}=D$. ambigua; so $=D$. subobscura; ma $=$ $D$. madeirensis; $\mathrm{gu}=D$. guanche $; \mathrm{bi}=D$. bifasciata $; \mathrm{ss}=S$. subsilvestris $; \mathrm{tr}=D$. tristis $; \mathrm{ps}=$ $D$. pseudoobscura; he $=D$. helvetica

dehydrogenase $(M d h) ; \alpha$-glycerophosphate dehydrogenase $(\alpha-G P D)$; isocitric dehydrogenase $(I d h)$; phosphohexose-isomerase $(P h i)$; alcohol dehydrogenase $(A d h)$; octanol dehydrogenase $(O d h)$; tetrazolium oxidase (two loci: To-1 and To-2); hexokinase (two loci: $H k-1$ and $H k$-3); peptidase (three loci: Pep-1, Pep-2 and Pep-3); glucose-6-phosphate dehydrogenase (G-6-PD); malic enzyme (Me); phosphoglucomutase (two loci: Pgm-1 and Pgm-2); diaphorase (Diaph); acid phosphatase (Acph); alkaline phosphatase $(A p h)$; aldehyde oxidase $(A o)$; leucine aminopeptidase (Lap); and xanthine dehydrogenase $(X d h)$. Buffer solutions and staining methods are those given by Loukas and Krimbas (1980) except for the enzymes: To for which a TRIS-Boric acid-EDTA solution ( $0 \cdot 18 \mathrm{M}$ TRIS + $0 \cdot 1 \mathrm{M}$ boric acid $+0.004 \mathrm{M}$ EDTA.2Na) was used as electrode buffer and a dilution 1:4 of this buffer for preparing the gels; Idh for which a TRIS-HCl solution $(0.25 \mathrm{M}$ TRIS, $p \mathrm{H}=8.5)$ was used as electrode buffer and a dilution $1: 4$ of this buffer for preparing the gels; Pep-2 for which instead of L-leucyl-Ltyrosine the dipeptide L-phenylalanyl-L-proline was used as a substrate; and $P g m-2$ for which a $0.041 \mathrm{M}$ sodium citrate solution $(p \mathrm{H}=7.5)$ was used as electrode buffer and a $0.005 \mathrm{M}$ histidine solution $(p \mathrm{H}=7.5)$ for preparing the gels. 
The adult stage was used in all enzymes studied except for Lap (pupal stage) and $A p h$ (third instar larvae).

For naming sites of activity, every allozyme band was identified by a number denoting the position of the band relative to the position of the band yielded by the most common allele of the species $D$. subobscura. Loci with similar in vitro enzymatic activity were distinguished by a number ( 1,2 or 3 ) denoting their succession from the origin: the smaller number indicating less migration.

\section{(ii) The strains}

The data for $D$. obscura are based on twenty-nine isofemale strains from Mt Parnes (Greece), nine from Karpenissi (Greece); five from Switzerland; one from Vitebsk (U.S.S.R.); and one from the Spanish Pyrenees (Caralps). For D. ambigua two strains from Karpenissi (Greece); one from Mt Parnes (Greece); two from Alma Ata (U.S.S.R.); and one from Switzerland were used. For $D$. subobscura we used isogenic strains kept in the Department of Genetics, Agricultural College of Athens, which carried the most common alleles of all the loci studied throughout the whole species distribution. We also analysed one strain of $D$. madeirensis and one strain of $D$. guanche (kindly provided by Professor Antonio Prevosti); two strains of $D$. bifasciata, one from Switzerland and one from Pavia (Italy); three strains of $D$. subsilvestris, two from Switzerland and one from Karpenissi (Greece); three strains of $D$. tristis from Switzerland; one strain of $D$. pseudoobscura from U.S.A.; and finally two strains of $D$. helvetica from Switzerland. Flies of all the available strains of each species were electrophoresed for each gene to establish the most common allele of the particular locus. Then, strains of all ten species, bearing the common alleles, were run side-by-side for the interspecies comparison.

\section{RESULTS}

\section{(i) Genetic polymorphism}

In table 1 are given the most common alleles of each species for all 24 loci. The negative sign in front of some alleles of the Adh locus indicates a cathodal migration. The capital letter $\mathrm{S}$ stands for a silent allele since no reaction was repeatedly observed in the gels.

The following twenty loci displayed very little or no intraspecies variation: 6-PGD-This enzyme yielded five different electrophoretic phenotypes. One strain of $D$. obscura and one of $D$. ambigua were found polymorphic. Mdh-The ten Drosophila species belong to seven different electrophoretic phenotypes. Two strains of $D$. obscura and two of $D$. ambigua were found to be polymorphic. (In this study a polymorphic strain for a particular locus always beats two alleles, one of which is usually the common one.) $\alpha-G P D$-This yielded two different electrophoretic phenotypes. Only one strain of $D$. obscura was found to be polymorphic. Idh-This enzyme classified the ten species into five electrophoretic phenotypes. Five strains of $D$. obscura displayed polymorphism for this locus. Phi-No intraspecies electrophoretic variation was detected. This enzyme yielded three different electrophoretic phenotypes. Adh-The ten species belong to five electrophoretic phenotypes. Ten strains of $D$. obscura 
were found to be polymorphic. Odh-No intraspecies electrophoretic variation was observed. The interspecies comparison revealed four different electrophoretic classes. To- 1 and To-2-No polymorphic strains were found for these two loci except for one $D$. ambigua strain for To-1. Both loci yielded three different electrophoretic phenotype. $H k$-1-Although $H k-1$ was invariant within species, among species it showed considerable variation. The ten species were classified into seven electrophoretic phenotypes. $H k_{-3}$-This yielded two electrophoretic classes. Intraspecies variation was detected only in $D$. obscura. Thus thirteen out of forty-five strains of $D$. obscura displayed two alleles, one of which was the common one. Pep-1This classified the ten species into seven electrophoretic phenotypes. Intraspecies polymorphism was detected in six strains of $D$. obscura and three of $D$. ambigua. Pep-2-No intraspecies variation was detected except for three $D$. obscura and for one $D$. subsilvestris strains. The interspecies comparison revealed six electrophoretic phenotypes. Pep-3-This also yielded six electrophoretic phenotypes. All the strains except for one D. ambigua strain were monomorphic. G-6-PD-Four strains of $D$. obscura and one of $D$. ambigua displayed polymorphism for G-6-PD. This locus grouped the ten species into four electrophoretic classes. Me-This classified the ten species into eight different electrophoretic phenotypes. No intraspecies variation was detected except for one D. bifasciata strain. Pgm-1-This yielded five electrophoretic phenotypes. Six strains of $D$. obscura and one of $D$. bifasciata were found polymorphic. Pgm-2-This displayed six different electrophoretic phenotypes. No intraspecies variation was detected. Diaph-The ten species were classified into three electrophoretic classes. No intraspecies variation was detected. Acph-The interspecies comparison revealed six electrophoretic phenotypes. Twelve strains of $D$. obscura, one of $D$. tristis and one of $D$. bifasciata were found to be polymorphic.

Finally, the following four loci displayed moderate or high intraspecies variation: $A p h-T h i s$ classified the ten species into seven distinguishable electrophoretic phenotypes. Sixteen strains of $D$. obscura, one of $D$. subsilvestris, one of $D$. tristis and one of $D$. ambigua were found to be polymorphic. Ao-This yielded six different electrophoretic phenotypes. Twenty strains of $D$. obscura, three of $D$. ambigua, one of $D$. bifasciata, one of $D$. subsilvestris and two of $D$. tristis proved to be polymorphic. Lap-This classified the ten species into eight electrophoretic phenotypes. Seventeen strains of $D$. obscura, one of $D$. ambigua and one of $D$. bifasciata were found polymorphic. $X d h$-The ten species belong to five electrophoretic phenotypes. Eleven strains of $D$. obscura, three of $D$. ambigua, one of $D$. bifasciata, one of $D$. subsilvestris and one of $D$. tristis were found to be polymorphic.

All the above remarks on the intraspecies genetic polymorphism do not concern $D$. subobscura, which has already been described by Loukas et al. (1979).

\section{(ii) Phylogeny}

Above the diagonal of table 2 we give the index of electrophoretic identity between the species $\mathrm{X}$ and $\mathrm{Y}, I_{\mathrm{XY}}$, which (in our case) is defined as the fraction of loci at which species $X$ and $Y$ share the same common allele. The corresponding genetic distances, $D_{\mathrm{XY}}$, with standard errors, $S_{D_{x Y}}$, are indicated below the diagonal (Nei, 1971). From the distance matrix 


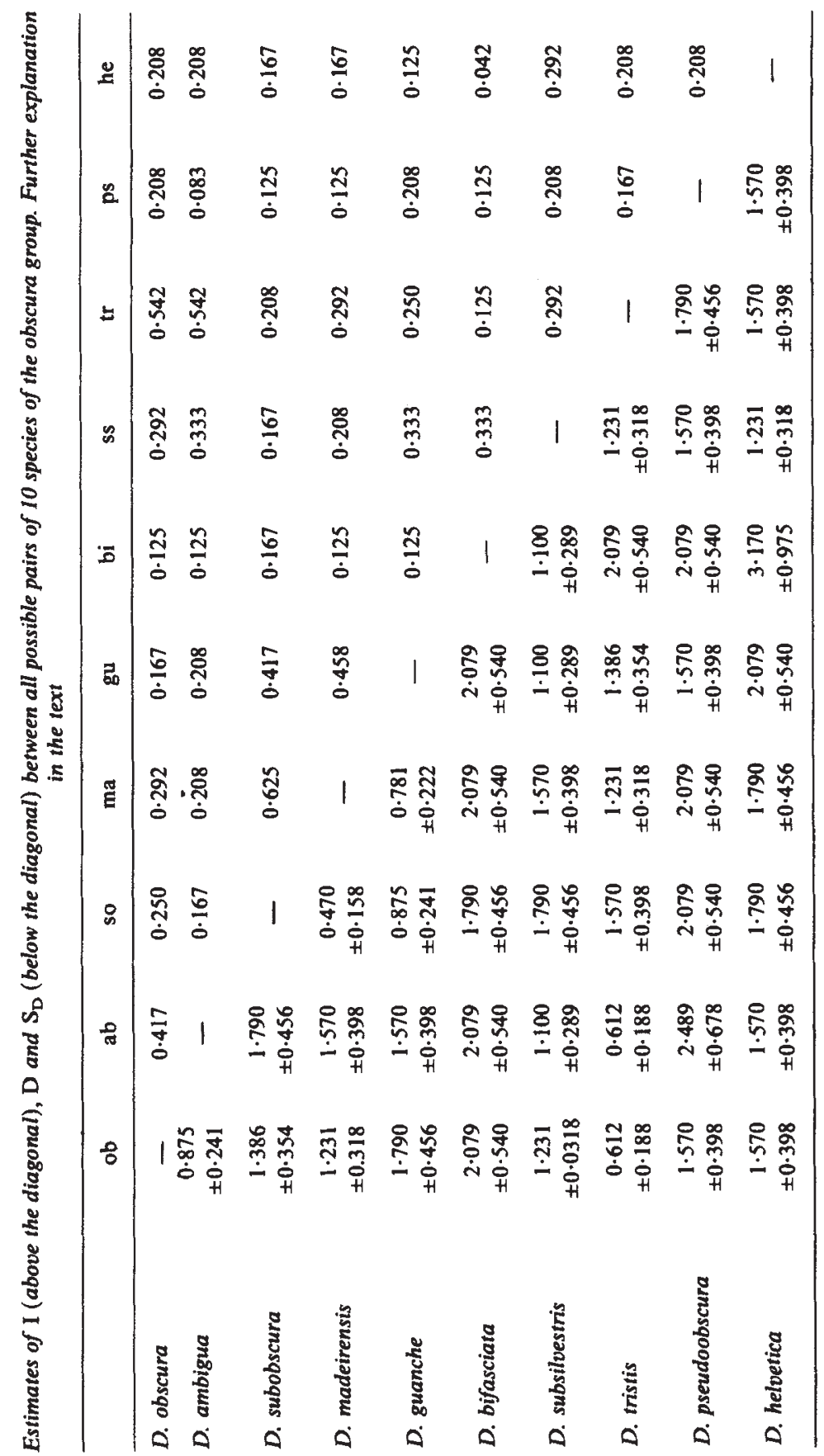




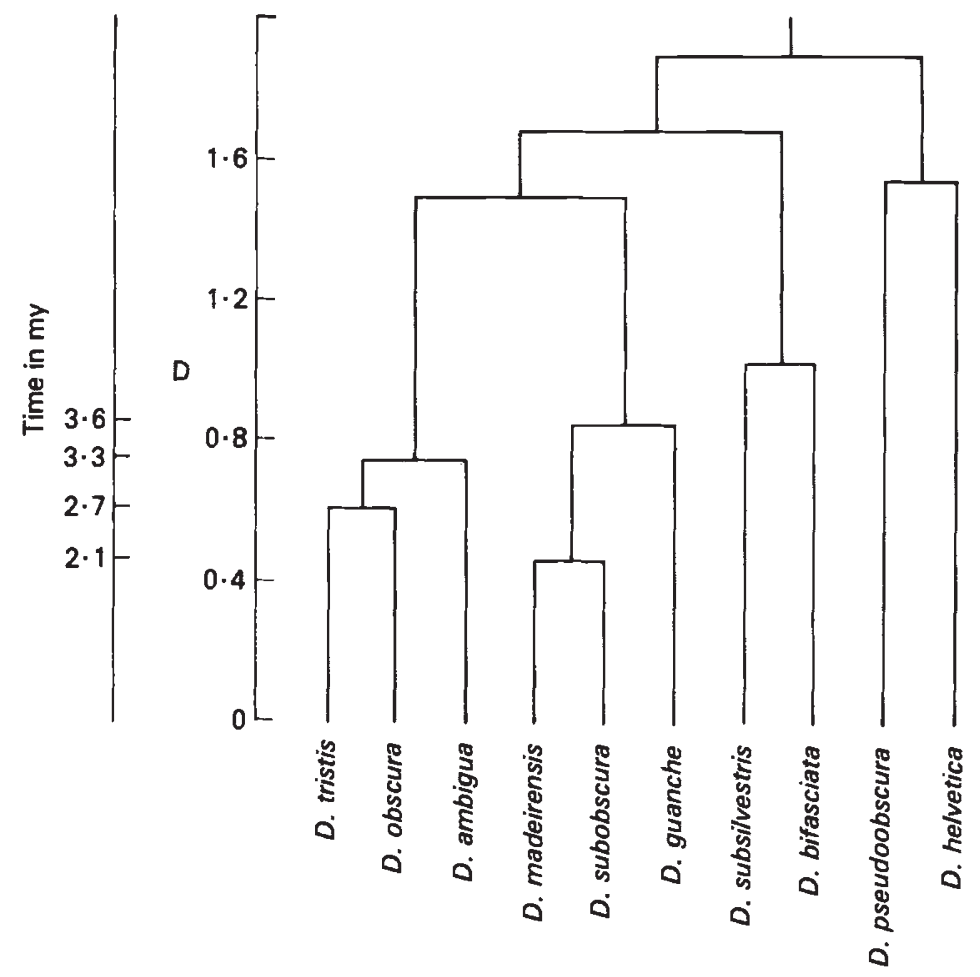

FIG. 1. A phylogenetic tree of ten Drosophila species of the obscura group. The time scale (in million years) is calculated as the mean of the two estimates indicated in the text.

of this table the phylogenetic tree of fig. 1 was constructed, according to the Unweighted Pair Group Mean Analysis (UPGMA) method of Sneath and Sokal (1973).

\section{Discussion}

From the electrophoretic data it follows that the gene $M e$ and, to a lesser degree, the genes $M d h, H k-r$ and $P e p-1$ can be used as genetic markers to distinguish most of the species belonging to the obscura group, not only because of the great number of the interspecies electrophoretic phenotypes which they yield but also because of their low degree of intraspecies genetic variation. It is the latter requirement which excludes $L a p$ as a good genetic marker. It must be noted that the simultaneous study of Pep-1 and Pep-3 could distinguish all species studied. (These two loci are stained on the same slab by the same substrate).

Lakovaara et al. (1976) in their latest paper on the phylogeny of the obscura group, which included nine of the ten species studied here, utilised 15 enzymatic systems corresponding to 21 loci, of which three were invariable between species.

Cabrera et al. (1983) utilised 30 enzyme systems corresponding to 67 loci to study the electrophoretic relationships among six species of the obscura group, five of which were in common with the present study. Our 
study includes 19 enzyme systems corresponding to 24 variable (between species) loci. In table 3 we indicate, for each locus, the mobility of the most common allozyme band of each species, starting from the fastest migrating band (at left) towards the slowest migrating one (to the right). Species which yielded allozymes with different mobilities are separated by semicolons, while a dash between two species denotes identical mobility of the corresponding allozymes. The data of Lakovaara et al. (1976) and Cabrera et al. (1983) presented here are restricted to the species in common with the present study: nine species for the first study [except for Acph, for which only seven species were studied (Lakovaara et al., 1972) and $A o$ and $X d h$, for which only eight species were studied (Lakovaara et al., 1976)], and five species for the second study.

The differences observed in the electrophoretic data among these three studies may be attributed:

(a) To the wrong choice of the common allele in each particular case. This is probably due to the small number of strains available for some of the species in each study. We tried to overcome this difficulty partially by using, for some of the species studied, strains from different localities. This difficulty is also partially overcome by the fact that the majority of the loci studied retain no or very little intraspecies variation.

(b) To the utilization of electrophoretic techniques with very little discrimination efficiency. This is obvious from the very small differences in migration of the allozymes reported by Lakovaara et al. (1976) in comparison to those of the present study. The same cause could also explain the differences in electrophoretic phenotypes, between the present study and that of Cabrera et al. (1983) as far as the species $D$. subobscura, D. madeirensis and $D$. guanche are concerned. It could be argued that these differences are due to the fact that we used only one strain for $D$. madeirensis and one for $D$. guanche while Cabrera et al. (1983) used samples from natural populations. We must, however, not overlook the fact that there is very little variation within $D$. guanche and $D$. madeirensis, when the same 22 genes (common in both studies) are considered (Cabrera et al., 1983). It is, therefore, difficult to admit that a single unselected strain showed homozygosity for a rare allele. Thus it seems that the greater number of identical bands detected by Cabrera et al. (1983), in all pairwise comparisons between the three species in question, is mainly due to electrophoretic techniques not permitting perfect discrimination. It must also be noticed that our strain of $D$. madeirensis is homozygous for a silent allele for Pep-1, the existence of which was not reported by Cabrera et al. (1983).

Pinsker and Buruga (1982) detected very little genetic variation in population samples of the species $D$. obscura, $D$. ambigua, $D$. subobscura. $D$. subsilvestris, $D$. tristis and $D$. helvetica for the loci Adh, $\alpha-G P D, I d h$, $M d h, M e, O d h, 6-P G D$ and $P g m$. However, their data are not included in table 3 since, except for a small difference concerning the electrophoretic phenotypes of the species $D$. subsilvestris and $D$. helvetica for the Pgm locus, all their electrophoretic data were identical to those of the present study. 


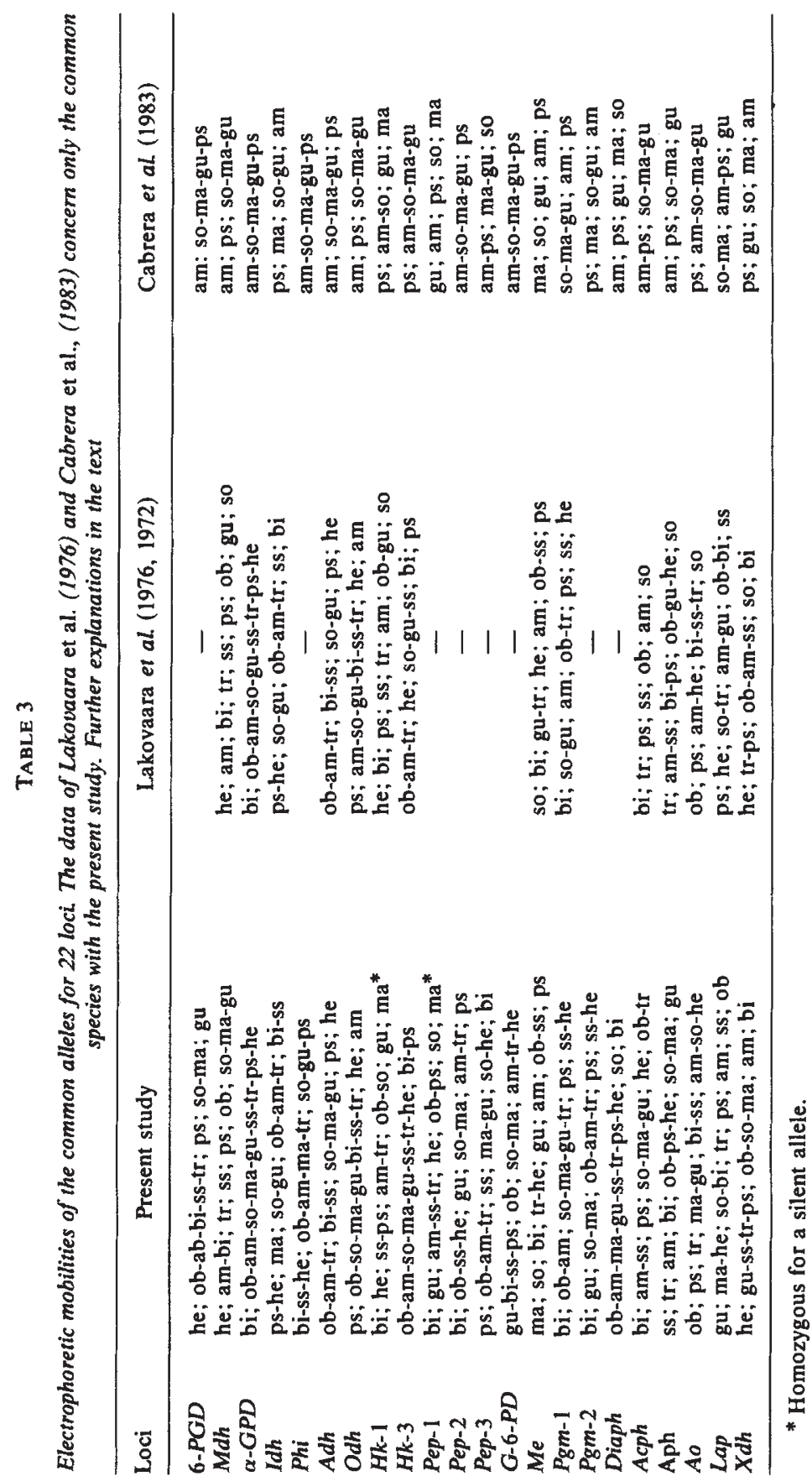


The most significant features of the phylogeny of fig. 1 are the following:

(i) There is a clear cut separation of the eight palearctic species of the obscura subgroup from the species $D$. helvetica and $D$. pseudoobscura.

(ii) The lineage leading to the obscura subgroup splits into two lineages. One lineage leads to $D$. bifasciata and $D$. subsilvestris; the other splits further into two sublineages: the sublineage of $D$. obscura, $D$. tristis and $D$. ambigua and the sublineage of $D$. guanche, D. subobscura and $D$. madeirensis. It is very important to note that, in this last sublineage, $D$. subobscura and $D$. madeirensis cluster together.

Thus, D. subobscura, D. madeirensis and $D$. guanche are apparently closely related species, a finding which agrees with the results of Krimbas and Loukas (in this issue). These authors examined the gene arrangements using the giant chromosomes of these three species and those of their $F_{1}$ hybrids. They found that $D$. subobscura is cytologically closer to $D$. madeirensis than to $D$. guanche, while $D$. guanche is closer to $D$. madeirensis. The comparison of $D$. guanche with $D$. madeirensis showed that there are 4 inversions unique to $D$. guanche and 2 inversion shared only by these two species $\left(\mathrm{O}_{3}\right.$ and a small distal inversion involving the section $16 \mathrm{BCD}$ of the A chromosome). On the other hand, the comparison of $D$. subobscura with $D$. madeirensis showed that these two species differ only by the two inversions which $D$. madeirensis shares with $D$. guanche. These findings also agree with the results obtained with interspecies crosses. Thus the only possible crosses between the three species in question were: \& $D$. madeirensis $\times{ }^{\circ} D$. guanche and $\& D$. madeirensis $\times \delta^{\circ} D$. subobscura. The first cross yielded a small number of $F_{1}$ sterile females and males and the second sterile $F_{1}$ males but fertile $F_{1}$ females which can be backcrossed to both parents.

The electrophoretic data presented in this paper, as far as the species $D$. subobscura, D. madeirensis and D. guanche are considered, do not support the conclusion of Cabrera et al. (1983), that $D$. madeirensis is more closely related to $D$. guanche than to $D$. subobscura. On the contrary, our data suggest a closer relation of $D$. madeirensis and $D$. subobscura which both are more apart from $D$. guanche. Although many more electrophoretic data, than those presented both by Cabrera et al. (1983) and the present study, would be needed to get an absolute certainty on the exact topography of the phylogenetic tree, it is significant to note that data based on chromosomal gene arrangements and on the possibility of obtaining interspecific hybrids are in absolute concordance with the electrophoretic data of the present study. This is a further suggestion on the correctness of the phylogenetic topology presented here.

Using the data presented by Lakovaara et al. (1976), concerning the nine species, common to both studies, we constructed a phylogenetic tree: this tree was found to be quite similar in topology to the tree depicted in fig. 1. Its only difference concerns the species $D$. subsilvestris which was found to be in the same group with $D$. ambigua, $D$. tristis and $D$. obscura (there is yet another branching, leading to $D$. subsilvestris, in the lineage of this group before this lineage gave rise to the three species in question). These matching results are due not only to the moderate similarity of the electrophoretic data reported in both studies, but also to the fact that usually 
the unique phenotypes displayed by a species for a particular locus differ in the two studies and the method applied recognises only identities, treating the same way differences in electrophoretic phenotypes. Thus the different unique phenotypes between the two studies (for the same species and locus) have exactly the same influence on the estimation of the genetic distances.

Marinkovic et al. (1977) constructed a phylogenetic tree of five species of the obscura group based on allelic frequencies of six loci only. They suggested a phylogeny in which $D$. subobscura is genetically more similar to the North American species D. pseudo-obscura and D. persimilis than to the two European species $D$. obscura and $D$. bifasciata. Also, Cabrera et al. (1983) found that D. ambigua is more closely related to American species $D$. pseudoobscura than to the cluster of species from the old world. (These two species can eventually hybridise). On the contrary, our results are in close agreement with those reported by Lakovaara et al. (1976): the palearctic species of the obscura subgroup cluster together and differ from the American species.

The phylogenetic tree can also be viewed in an absolute time scale. It is possible to get approximate time divergence estimations in million years from the genetic distances. For this purpose we intend to use a method employed in vertebrate studies in spite of the fact that it is not quite clear whether this calibration applies also to insects. Thus, when $D$ is smaller than 0.2 the time in years is very roughly equal to $D \times 5 \times 10^{6}$, when one fourth of the amino acid substitutions is electrophoretically detected, or $D \times 3.75 \times 10^{6}$ when one such third is distinguished (Nei and Roychoudhury, 1982). In this study, only one buffer system was used for every enzyme locus, but the most adequate for it. Since a very tedious amount of repeated electrophoreses, in all kinds of species combinations, was performed in order to get direct comparison between every possible pair of species running one next to the other, and since repeated electrophoreses were performed with different durations of time when a suspected small difference in mobility was observed, we feel that in our case the multiplication factor lies somewhere between these two values. $D$, however, is in all cases higher than $0 \cdot 2$. Thus the times noted in the scale of fig. 1 should be taken only as indications of orders of magnitude. It seems that $D$. subobscura and D. madeirensis, the pair of most closely related species studied by us, diverged more than 2 million years B.P.

Acknowledgements. We would like to thank Drs A. Prevosti, M. Monclús-Prevosti, for kindly providing us strains of $D$. guanche and $D$. madeirensis, H. Burla, H. Jungen and $G$. Bächli, for sending us strains of obscura group species from Switzerland. Mr J. Sourdis developed the computer program to construct the phylogenetic tree and Mrs G. Kolia maintained the strains successfully, especially $D$. helvetica. The cost of this research was only partly defrayed by grant from the Hellenic National Research Foundation.

\section{REFERENCES}

CABRerA, V. M., Gonzalez, A. M., LARRUgA, J. M. AND GUllon, A. 1983. Genetic distance and evolutionary relationships in the Drosophila obscura group. Evolution, 37, 675-689.

KRIMBAS, C. B., AND LOUKAS, M. 1983. Evolution of the obscura group Drosophila species. I. Salivary chromosomes and quantitative characters in $D$. subobscura and two closely related species (in this issue). 
LAKOVAaRA, S. AND SAURA, A. 1982. Evolution and speciation in the Drosophila obscura group. In Ashburner, M., Carson, H. L. and Thompson, J. N. Jr. (eds.) The Genetics and Biology of Drosophila, Vol. 3b, Academic Press, London, pp. 2-59.

LAKOVAARA, S., SAURA, A. AND FALK. C. T. 1972. Genetic distance and evolutionary relationships in the Drosophila obscura group. Evolution, 26, 177-184.

LAKoVAaRA, S., SAURA, A., LANKINEN, P., POHJOLA, L. AND LOKKI, J. 1976. The use of isoenzymes in tracing evolution and in classifying Drosophilidae. Zoologica Scripta, 5, 173-179.

LOUKAS, M. AND KRIMBAS, C. B. 1980. Isozyme techniques in Drosophila subobscura. Dros. Inf. Serv. 55, 157-158.

LOUKAS, M., KRIMBAS, C. B., MAVRAGANI-TSIPIDOU, P. AND KASTRITSIS, C. D. 1979. Genetics of Drosophila subobscura populations. VIII. Allozyme loci and their chromosome maps. J. Hered., 70, 17-26.

MARINKOVIC, D., AYALA, F. J. AND ANDJELKOVIC, M. 1977. Genetic polymorphism and phylogeny of Drosophila subobscura. Evolution, 32, 164-173.

NEI, M. 1971. Interspecific gene differences and evolutionary time estimated from electrophoretic data on protein identity. Am. Nat., 105, 385-398.

NEI, M. AND ROYCHOUDHURY, A. K. 1982. Genetic relationship and evolution of human races. Evolutionary Biology, 14, 1-59.

PINSKER, W. AND BURUGA, J. 1982. Comparative study of allozyme variation in six species of the Drosophila obscura group. Z. zool. Syst. Evolut.-forsch., 20, 53-63.

SNEATH, P. H. A. AND SOKAL, R. R. 1973. Numerical Taxonomy. W. H. Freeman, San Francsico.

TAKAMORI, H. AND OKADA, T. 1983. Drosophila tsukubaensis, a new species of the obscura group of the genus Drosophila (Diptera, Drosphilidae) from Japan. Kontyû, Tokyo, 51 , 265-268. 